This item was submitted to Loughborough's Research Repository by the author.

Items in Figshare are protected by copyright, with all rights reserved, unless otherwise indicated.

\title{
Self-starvation and the performance narrative in competitive sport
}

PLEASE CITE THE PUBLISHED VERSION

http://dx.doi.org/10.1016/j.psychsport.2013.10.014

\section{PUBLISHER}

(c) Elsevier Ltd

\section{VERSION}

AM (Accepted Manuscript)

\section{PUBLISHER STATEMENT}

This work is made available according to the conditions of the Creative Commons Attribution-NonCommercialNoDerivatives 4.0 International (CC BY-NC-ND 4.0) licence. Full details of this licence are available at: https://creativecommons.org/licenses/by-nc-nd/4.0/

\section{LICENCE}

CC BY-NC-ND 4.0

\section{REPOSITORY RECORD}

Papathomas, Anthony, and David E. Lavallee. 2019. "Self-starvation and the Performance Narrative in Competitive Sport”. figshare. https://hdl.handle.net/2134/17176. 
Running Head: Self-starvation and the performance narrative

1

2

Self-starvation and the performance narrative in competitive sport

3

4

5

6

7

8

9

10

11

12

13

14

15

16

17

18

19

20

21

22

23

24

25 
Self-starvation and the performance narrative

1

2

3 OBJECTIVES: To provide an alternative to medical understanding of disordered

4 eating in sport through an emphasis on personal perspectives.

5 DESIGN: This study draws on narrative theory to interpretively analyse the life of

6 Holly, a female athlete who engages in severe self-starvation.

7 METHOD: More than 7 hours of life history data was gathered over a period of 8

8 months through unstructured interviews. Holly’s story was analysed through

9 principles of narrative analysis, with attention afforded to both narrative content and 10 structure.

RESULTS: Holly's life is characterised by a struggle to align her life experiences with a culturally specified "performance narrative” that lauds normative success. When neither her academic nor sporting endeavours are perceived to fulfil the achievement narrative, Holly is thrust into emotional turmoil and begins to conceive of self-starvation as a means to achieve.

CONCLUSION: The performance narrative spans both academic and sporting cultural domains and it can play a role in athlete disordered eating. (1)

Key words: Narrative, eating disorder, anorexia nervosa, self-starvation, sport 0 1 22 3 4 5 
Self-starvation and the performance narrative

\section{Self-starvation and the performance narrative in competitive sport}

The eating disorders in sport literature base suggests that pressures to be thin

for performance gains saturate the sporting environment and this places athletes at increased risk of eating disorder development (Dosil, 2008). Athletes considered most vulnerable are elite females participating in "lean sports”, such as figure skating and gymnastics, where the focus on weight and thinness is particularly overt (Smolak, Murnen, \& Ruble, 2000). A variety of prevalence studies support this sport-eating disorder relationship and point towards as much as twice as many athletes than nonathlete controls possessing clinical eating disorders (Torstveit, Rosenvinge, \& Sundgot-Borgen, 2008). Due to a dearth in risk factor studies however, there are few certainties as to the exact mechanisms that lead to the occurrence of eating disorders or disordered eating in athletes (Petrie \& Greenleaf, 2007) and only speculative accounts exist regarding athlete specific treatment provision (Currie, 2007).

Understanding athlete eating disorders continues to be a partial affair.

The wider eating disorders literature has been criticised for an unduly narrow medicalized approach that fixates on symptoms and causes and marginalises understanding of experiential features (Botha, 2009). The danger here is that scientific knowledge becomes detached from those it was intended to treat (Frank, 2007). This detachment can be dehumanising (Rich, 2006). This is also a problem in the sport psychology eating disorders literature where medical approaches have been adopted widely and uncritically (see Papathomas \& Lavallee, 2012). According to Busanich and McGannon (2010), the objectivist principles of medical science portray disordered eating as primarily an individual pathology rather than something that is also heavily influenced by social, historical and cultural factors. These authors argue that to extend knowledge in this field, researchers must attend to the personal 
Self-starvation and the performance narrative

1 “meanings behind athletes' eating and body practices and the psychological effects

2 that result” (p. 401). These “meanings” have been largely neglected by scholars.

Frustrated by the singular way in which eating disorders have been

4 understood, a small number of researchers, within both general psychology and sport

5 psychology, have sought to offer an alternative perspective. Within general

6 psychology, Shohet (2007) produced a detailed narrative analysis of interview data

7 drawn from 3 females with experiences of anorexia nervosa. Shohet identified two

8 narrative types she referred to as the "fully recovered" and the "struggling to recover"

9 narratives. The fully recovered narrative was characterized by stability and coherence.

10 A coherent narrative is a complete one and involves an explanation of consequence. A

11 coherent narrative becomes stable when it is fully accepted and less subject to change.

12 The fully recovered narrative was stable because it was typically drawn from popular

13 and robust cultural understandings of why eating disorders occur (e.g. perfectionism).

14 With a ready-made explanation internalized, individuals could focus on recovery. The

15 struggling to recover narrative was considered more authentic than stable, with tellers

16 more critical of mainstream explanations and more likely to ponder the complexity of

17 experience. These individuals often understood their eating disorder as both good and

18 bad. For Shohet, this lack of narrative coherence made it difficult for individuals to

19 commit to a particular recovery route. The implications are that how an eating

20 disorder is understood narratively impacts the way it is experienced in the future.

21 A further narrative account explored the lives of 4 women with anorexia

22 nervosa from an emotional and relational perspective (O’Shaughnessy, Dallos, \&

23 Gough, 2013). Drawing on life-story data, the following broad narrative themes were

24 identified: 1.) loneliness 2.) threatening environments 3.) difficulty imagining

25 perspectives of others 4.) relationships troubles and 5.) narrative incompleteness. The 
Self-starvation and the performance narrative

1 authors emphasised that these contextual insights enrich our understanding of eating

2 disorders and would not have been possible had they adopted a medical focus. None

3 of the women's stories drew from popular, mainstream theories to explain their

4 anorexia but rather constructed their experience in terms of troubled relationships.

5 One of the most pertinent findings of the study concerned the overarching impact of

6 narrative constructions on life with an eating disorder. Echoing Shohet’s (2007)

7 principle argument, how women made sense of the past, shaped their "psychological

8 defences for coping with current events and in turn shaping their futures” (p. 57). An

9 incomplete story, essentially narrative incoherence, contributed to participant

10 vulnerability and an inability to move on.

11 There has also been a recent uprising of qualitative work within eating

12 disorders in sport. For example, Papathomas and Lavallee (2010) adopted an

13 interpretative phenomenological analysis to study female athletes' disordered eating

14 experiences. The interpretive focus allowed athletes to communicate their own

15 understandings of eating disorders in sport. It was shown that athletes' concerns went

16 beyond well-documented symptomatology to focus on more general issues such as the 17 struggle to disclose mental illness, a perceived lack of social support, and difficult

18 identity challenges. Again, these unique and unforeseen insights would not have been

19 possible through more prescriptive, medicalized research.

In an earlier study, Papathomas and Lavallee (2006) conducted a life history

21 analysis of a male athlete diagnosed with bulimia nervosa. The participant in this

22 study, a former elite youth soccer player called Mike, engaged in over 11 hours of

23 one-to-one, loosely structured interviews. Affording such an extended time period

24 allowed Mike the freedom and flexibility to construct a rich and detailed narrative

25 account. A key contribution of this research was identifying the role of Mike's 
Self-starvation and the performance narrative

1 narrative in helping him understand this painful experience. By explaining the eating

2 disorder as a means to personal growth, the illness was given a purpose. In direct

3 contrast to the incomplete stories told by the women in the O’Shaughnessy et al.

4 (2013) study, as well as some of those in Shohet's (2007) research, Mike's narrative

5 was coherent and therefore meaningful. This narrative understanding was associated

6 with Mike accepting his illness, committing to recovery and moving on with his life.

Busanich, McGannon, \& Schinke (2012) showed how personal narratives

8 might shape the development of unhealthy eating behaviors. Their analysis explored

9 how both males and females come to understand the relationship between food, the

10 body and exercise. This study highlighted that the performance narrative of elite sport,

11 a dominant cultural storyline whereby only success and achievement leads to self-

12 worth and self-identity, was associated with negative body-image, weight obsessions,

13 calorie deprivation and extreme forms of exercising. The notion that a culturally

14 popularized narrative can influence eating behaviours is another important step in

15 theorizing athlete eating disorders differently.

The aim of the present study is to provide an alternative, complimentary

commentary on eating disorders. We explore the growing belief that personal

narratives are important in medicine (Charon, 2006) and in mental illness (Carless,

2008). We propose that a move away from medicalized perspectives, towards a more meaning-focused approach, can provide new insights into the experience of eating

21 disorders and disordered eating. To achieve this, a narrative analysis is applied to life story data constructed by Holly, a female athlete engaging in regular acts of selfstarvation. An in-depth focus on a single case, as opposed to briefer accounts of numerous participants, is an important strategy when exploring a person's intricate 
Self-starvation and the performance narrative

1 an eating disorder are disproportionately underrepresented in the literature and as a

2 result there is a lack of appreciation for the broader, contextual facets of the illness.

3 This study asks specifically; what are the broader, contextual factors of athlete

4 disordered eating? Holly’s story was of particular interest as she participated in

5 netball and basketball; two sports perceived as low-risk for eating disorder

6 development and hence often overlooked. From a narrative perspective, an

7 exploration of the life story can shed light on the manner in which personal, social and

8 cultural influences interact to shape narrative construction. The study also seeks to

9 illuminate how a constructed narrative impacts on identity, experience, and action.

\section{Methodology}

11 Narrative Inquiry

Narrative inquiry involves the analysis of the stories people tell as a way of understanding experience and action (Polkinghorne, 1995). With a focus on socially constructed personal meanings, narrative inquiry is typically underpinned by a relativist ontology and an interpretivist epistemology (see Sparkes \& Smith, 2013 for a detailed discussion on these philosophical concepts). In contrast to many other forms of qualitative inquiry, which focus exclusively on thematic content, narrative inquiry also views the overarching structure of a story - its basic plot - as an important analytical feature. Smith and Sparkes (2009) have identified numerous reasons why narrative

21 inquiry can be useful and beneficial for sport and exercise psychology research. We now draw on some of those reasons with specific reference to how the eating disorders in sport literature can be advanced. In the first instance, Smith and Sparkes emphasise that the interpretive assumptions that inform narrative inquiry can help enlarge the narrow methodological repertoire that characterises much of sport 
Self-starvation and the performance narrative

1 psychology. As we have argued, this is a particularly valid rationale for eating

disorders research which is dominated by a medicalized form of scientific inquiry that can limit other ways of knowing.

Second, narrative inquiry encourages "a focus on the ways relations between people shape, enable and constrain lives” (Smith \& Sparkes, 2009, p. 6). It acknowledges that interactions with others are crucial to constructions of meaning and experience. This relational focus provides a useful counter-perspective to psychology's tendency to individualize eating pathology. It allows for the exploration of how significant others, such as coaches, fellow athletes and family members, might impact on how an athlete interprets and duly experiences life with an eating disorder. Third, narratives are sensitive to both the personal and social auspices of human experience. People’s life stories are imprinted with idiosyncratic details that reflect personal circumstances and the specific context of the teller's perceived world. It is exactly these personal details of experience that are noticeably absent from current understandings of athlete disordered eating. At the same time, these unique stories are always social, in terms of being relationally constructed and in that they are mediated by the conventional narrative resources culturally available. Smith and Sparkes (2009) address the connection between the personal and social when they state that “a person’s own story and their experiences is shaped, facilitated, and constrained by narratives that circulate within the culture that he or she is immersed" (p. 5). Tending to the role of cultural narratives in shaping experience provides an additional layer of insight into how athletes make sense of their disordered eating. Finally, Smith and Sparkes (2009) outline how narrative approaches to research are closely aligned with issues of self and identity. Narrative theorists proclaim that identities are constructed through narrative and the stories people tell 
Self-starvation and the performance narrative

1 others. Like narrative then, identity is a relational production that is constructed continuously within social interactions. The concept of narrative identity is important as it concerns how constructed meanings of experience can impact on the self. With regards to this study, how stories of disordered eating impact on athlete identity represents another unique avenue from which to explore the experience.

\section{The Participant}

Holly (a pseudonym) is a 20-year-old undergraduate student who currently competes to an elite level in basketball. Through her high school years, Holly primarily competed in netball. She volunteered to partake in this study by answering recruitment materials that sought athletes with experiences of disordered eating in sport. During the early exchanges of our first meeting, it seemed that Holly's experience strayed little from that typically described within the athletes with eating disorders literature (e.g. Dosil, 2008). Like many athletes, she possessed concerns that gaining weight may detrimentally interfere with her sporting performance. As she proclaimed: "that was my first thought, lose some weight and get better...I don't like eating and playing sport. If I do, I feel massive guilt about it”. It soon became apparent that sporting pressures to be thin represented just one element of what was a more complex story with multiple, at times ambiguous and contradictory, meanings. Holly's frequent and often prolonged acts of self-starvation have never received a formal clinical diagnosis and cannot be labelled an "eating disorder”. Accordingly, we use the term “disordered eating” to describe Holly’s eating behaviours with the proviso that this in no way indicates these behaviours to be less severe or less problematic than a clinically defined eating disorder. It is the ethos of this meaning-centered report that clinical categorisation assumes less relevance than Holly’s subjective view that her eating experience has been, and is, a significantly 
Self-starvation and the performance narrative

1 troublesome one. Holly described her current eating behaviours in the following way:

“it's not great at the minute, kind of just getting by on the bare minimum...I don't

3 know, sometimes it's easier than others to stay on top of it. I could go a day without

4 realizing that I hadn't eaten anything... a lot of the time I just don't realize, I just

5 don't get hungry and sometimes it's just I might be hungry I just don't want to eat."

\section{Life history interviews in action}

The life history interview, which is typically informal, loosely structured and

8 highly interactive, represents a popular method of data collection within narrative

9 inquiry (Plummer, 2001). Life history interviews place the emphasis on the participant

10 and encourage him or her to tell their own story in their own words. This unique

11 approach to qualitative research has been used successfully in sport and exercise 12 psychology across a range of topics (see Douglass \& Carless, 2009; Papathomas \&

13 Lavallee, 2006; Phoenix \& Smith, 2011). The majority of these studies engaged each

14 of their participants in more than one life history interview. The increase in interview

15 time provides flexibility, supports deep reflection, and promotes effective narrative

16 construction in a way one-off, structured interviews cannot.

Across a period of 8 months, I (first author) conducted a series of 6 interviews with Holly yielding a total of over 7 hours of digitally recorded data. Each interview lasted between 60 and 90 minutes and took place at my on campus university office. In accordance with university granted ethical approval, Holly received a participant

21 information sheet detailing the nature of the study and her involvement in it prior to interviews taking place and she was asked to sign an informed consent form. The first interview was an opportunity to introduce Holly to the interview setting and accustom

24 her to the interview experience rather than to discuss eating issues. It was also a chance to begin to build rapport and gain the feelings of respect and trust that are 
Self-starvation and the performance narrative

1 necessary if an individual is to share the intimate details of a life. Although few hard

2 and fast rules exist on achieving rapport, Cole and Knowles (2001) suggest principles

3 of relationality, mutuality and empathy should guide the life history interview process.

To begin eliciting the life history narrative, at the start of the second interview,

5 Holly was simply invited to describe some of her earliest memories. Holly responded

6 by discussing her early school years and from here I encouraged Holly to describe,

7 expand on, and provide examples of the issues she deemed relevant. Digressions were

8 welcomed with no attempts made to interrupt Holly and steer her back to a given

9 issue. Allowing Holly this freedom provided an effective means for gaining a wealth

10 of contextual information. Other useful and regularly called upon probes, such as

11 "how did/do you feel about that?” and "what did/does that mean to you?” encouraged

12 Holly to speak of her feelings and emotions and reflect on what personal

13 understanding she holds for important biographical events. On completion, each

14 interview was transcribed verbatim and forwarded to Holly for her perusal. Holly was

15 asked to comment via email if she felt the transcript was inaccurate in anyway, if she

16 felt she had been misinterpreted and if she felt she would like to add or clarify an

17 issue. Holly made no changes regarding content but commented at the usefulness of

18 reading the transcripts in terms of understanding her own story.

19 Narrative Analysis

20 Our narrative analysis drew on the work of Reissman (2008) and involved two

21 complimentary forms of narrative analysis; thematic and structural. In a thematic

22 analysis the focus is on the specific content of "what" is said by the participant.

23 Unlike other forms of thematic analysis (e.g. those involved in grounded theory or

24 interpretative phenomenological analysis), thematic narrative analysis offers insights

25 that reflect the case as a whole rather than specific categories. As such, Holly's story 
Self-starvation and the performance narrative

1 was left intact and there is no "table of themes" presenting isolated conceptual categories. To conduct the thematic narrative analysis, each transcript was read repeatedly after each interview. A process of coding was undertaken whereby annotations, summarising what Holly had said, were handwritten on the transcript. A combination of interpretive codes and direct codes was made. Interpretive codes were made in the left margin and incorporated conceptual insights based on psychological and narrative theory. For example, the code "identity loss" might be used to depict part of the story, albeit Holly may not have used this exact term herself. Direct codes were made in the right margin and directly reflected Holly's exact words. For example, if Holly specifically described an experience of anger, a code such as "angry at school” was applied. An independent thematic narrative analysis was conducted for each interview transcript If a thematic analysis addresses the specific events and contextual details of a story, a structural analysis is concerned with its broad genre. Reissman (2008) argues that "a structural analysis can generate insights that are missed when interpretations focus narrowly on "what” is said, ignoring how content is organised by a speaker" (p. 100). Narrative structure is an important unit of analysis as it is the "types" of narrative told that shape experience and action. For example, a "tragic” narrative structure, whereby the central character fails to overcome challenges, invariably constructs lived experiences as painful and future efforts as futile (see McAdams, 1993). The structural analysis in this study began with repeated readings of the interview transcripts, during which an overarching narrative plot for Holly’s story was sought. Further, it was important to be open to sub-plots and "narratives within narratives” in addition to sensitizing towards a central storyline. This allowed us to detect a narrative structure that was contradictory, uncertain or even disrupted. Once a 
Self-starvation and the performance narrative

1 narrative structure was identified, transcripts were reviewed in order to identify and

2 select specific extracts that best illustrated this structure. This process ensured Holly's

3 personal story and the broader cultural narrative, as well as the interplay between

4 them, is communicated to the reader in the subsequent section.

5

\section{Interpretation and Discussion}

This section integrates the intricacies of Holly's constructed narrative with the elements of narrative theory and existing eating disorders research that have helped to inform interpretations. We suggest that this approach adds clarity to the way our analysis relates to Holly’s story.

\section{The performance narrative}

The central theme throughout Holly's life is one of striving to meet the expectations of others. It is a quest for success in an achievement-oriented world. This is characterized, and underpinned by, a fundamental desire for the recognition and acceptance achievement might bring from significant others, the immediate family in particular. Reflecting on the first three of our interviews, Holly acknowledged the intensity with which notions of achievement and failure persist in her life story and therefore impact on her identity - "I start seeing trends when I'm speaking, like I talk about obviously achieving and failing a lot and I think that definitely linked with how I felt about myself'.

Delving into the specifics of the narrative, the following extract illustrates how Holly came to understand the emergence of her preoccupation with achievement as partly a consequence of joining the same high school as her high achieving brother. Holly: ...he (brother) was going into year 11 and had just been given head boy and was obviously quite well known throughout the school. So to go in at year 7 and have that was quite daunting. 
Self-starvation and the performance narrative

AP: Was it something you were wary of before starting? Holly: ...yeah I mean I knew he was top set for everything. He was already looking to think about top universities and he’s really smart, so going in I was a bit like am I going to have to live up to something here? Teachers would see my surname and say “oh your Stephen’s sister”...I have vivid memories of having my first maths test and then the teacher saying “oh your Stephen’s sister, we expect a lot”. So there was definitely a bit to live up to. At the school they have exams straight away and they set you from that first week. So coming up to that was pretty nerve-racking...I was pretty on edge. I mean it goes from 1 to 4 and I was middle set for everything and it becomes like a hierarchy, so you don't really mix with the kids from the top band and to have my brother being top setted for everything I was pretty disappointed in where I was...I think the way they just, first week, they're just like bang, we're all just setted like that, it's a bit...interesting.

This segment of Holly's narrative is located within the "public narrative" of the education system. Somers (1994) states that public narratives are "attached to cultural and institutional formations larger than the single individual” (p. 619). Her theoretical position implies that public narratives inform and shape our personal, or what Somers terms “ontological”, narratives. To explicate, our stories are not entirely our own but rather influenced by the narratives available through wider cultural contexts. In turn, Somers argues that public narratives are themselves influenced by a higher power; “masternarratives”. Masternarratives exist on a societal, even global level, and often operate beyond our consciousness. Returning to Holly, her new school presented a cultural context with an overt public narrative - one where academic excellence is the chief value system. In line with Somers, Holly adopts the ideals upheld by this public 
Self-starvation and the performance narrative

1 narrative for her own story. This process was facilitated by numerous institutional

2 actions; immediate assessment, the hierarchical grouping of students according to

3 academic ability, and the existence of head boys based on academic prowess. The

4 essence of this "performance narrative" is that worth and status is dependent on

5 scholarly success. It parallels the performance narrative associated with elite sport

6 which is defined as a story of dedication to sporting achievement to the exclusion of

7 other areas of life (Douglas \& Carless, 2009).

Public narratives are also communicated to individuals interpersonally or

9 through "webs of relationality” (Somers, 1994, p. 618). For example, Holly’s brother

10 Stephen personifies the performance narrative and his presence at the school provides

11 a constant reminder of it, illuminating the discrepancy between her own experience

12 and what is culturally expected. Holly also stated that teachers related to her in terms

13 of her brother's superior achievements. A number of scholars have theorised that

14 identity is relationally constituted and that we come to know the self through a myriad

15 of interactions across the lifespan (e.g. Gergen \& Gergen, 1988; Polkinghorne, 1988).

16 Holly therefore, duly adopts these negative comparisons with her brother and begins

17 to conceive of herself this way too; as someone who falls short.

18 Holly's relational-self concerns her identity as co-constructed through

19 interactions with others. This relational identity was impacted by an abusive female

20 schoolteacher who was also her basketball coach. Holly described the teacher as

21 having a personal vendetta against her:

for some reason she made it her mission to every minute she could of the day to you know “you're not as good as your brother”, “you'll never amount to anything”, I didn’t know any better so I thought maybe she’s right and just took it and just day-to-day that was how it went for a really long time... 
Self-starvation and the performance narrative

1 Set against the backdrop of the school's focus on achievement and Holly's academic insecurities in relation to her brother, the teacher's comments were hurtful and magnified Holly’s sense of inferiority. Holly illustrates how these negative evaluations were involved in the co-construction of self when she gives them credence by stating “maybe she’s right”. Holly narrated numerous stories of this teacher's tirades, each of which served to cement Holly’s feelings of failure. Exacerbating the situation, Holly's family unit acts as an additional public narrative that reinforces the narrative exalted at school:

AP: What was the reaction at home towards you being in the middle set? Holly: ...they'd never have said they were disappointed...but sometimes you can tell. It was kind of you know "oh good but can you work harder to get higher up?” and sometimes it was just like “I’m happy where I am”. I think to have one kid go through and do so well they almost expected the same again. In my family that was always the important thing... it was always about the academics, that was what you needed to be good at. I kind of grew up with that so when I suddenly realised I was kind of just averaging with everyone else and the idea at home was that I should be doing a lot better. I should be above average. Then to not be I definitely felt I was being a bit of a let down Holly's story depicts the emphasis on academic excellence that resonates through her family institution. The narrative path is explicitly presented when she is asked to “work harder to get higher up”. Providing her parents with a speaking role suggests Holly is keen to externalise this narrative line and separate it from her own perspective. In support of this interpretation, Holly’s own speaking role rejects performance narrative as she claims “I'm happy where I am”. This crucial tension, between how she sees it and how her parent see it, is emphasised further when Holly 
Self-starvation and the performance narrative

1 claims that better academic performance was not her own desire but rather "the idea

2 at home". Such is the influence of the family however, Holly's own conceptions of

3 achievement hold little sway and she ultimately feels she is a disappointment when

4 her performance strays from the narrative path encouraged by her parents.

Given that public narratives act as social matrices used to shape our own

6 personal narratives (Somers, 1994), Holly comes to understand her experiences within

7 the framework of the narrative forces of education and family. As her experiences

8 belie the performance narrative promoted by these institutions, she has few options

9 but to conclude that she is not a successful achiever, but rather, implicitly, an unsuccessful failure. This message was emphasised throughout Holly’s school life in

11 both overt and covert ways and led to what she described as a "breakdown" and a “downward spiral”. As argued by McLeod (1997), when personal experience is misaligned with the cultural story an individual is a part of, crisis ensues.

\section{A quest for narrative realignment: Striving to perform}

In this section we identify Holly's attempt to realign her experience with the performance narrative of academia and the role of the performance narrative of sport in this process. Holly's initial efforts at narrative realignment involved working hard to improve her academic performance at school but when success was not forthcoming Holly became disillusioned and "rebelled against the whole system". Interest and motivation in lessons waned and she became disruptive in class. She explained: "I wasn't going to get any better so I just thought why not just not even try because then I don't feel like I'm failing". In effect, Holly described a conscious attempt to disengage with the performance narrative through a withdrawal of academic effort. In theory, if she outright rejects the narrative and its associated values of hard work and progress, she can no longer be judged against it and this 
Self-starvation and the performance narrative

1 might alleviate feelings of failure. Public narratives are not easily escaped however

2 and this tactic only served to draw attention to the errant nature of her experience in

3 comparison to the cultural norm.

Holly’s sporting prowess presented an alternative means for her to perform

5 and this enabled her to feel "good about being good at the sport rather than always

6 thinking I'm not so great”. With academic performance renounced, the performance

7 narrative associated with competitive sport (see Douglass \& Carless, 2009) became

8 the next opportunity to realign with cultural expectations of success and achievement.

9 Holly duly participated successfully in an array of school sports but particularly

10 excelled in basketball and netball. Sport seemed to provide Holly with a level of

11 kudos that she could never attain in an academic setting - "within the sports area of

12 the school I was well known...it was nice to be given a responsibility in one part of

13 the school if it wasn't going to be in the area of academics". Holly's achievements in

14 sport could be accepted on their own merit and, for the first time, illuminated her

15 personal identity to herself and to others. Holly developed an athletic identity, fully

16 identifying with the athletic role and its related social status (Brewer, Van Raalte, \&

17 Linde, 1993). This partial success in realigning Holly’s experiences with the

18 performance narrative was quickly quashed by her parents' view that sporting

19 accomplishments were inferior to academic ones - "it was more just a hobby to be

20 good at sport...it should have been that I was good at the academics and not the other

21 way round”. This accentuated Holly's crisis, threatened her athletic identity and

22 compounded her feelings of failure. Her experiences seemed destined to continue

23 running awry to the performance narrative projected by her family.

24 Holly soon became depressed and, as she had done with school, completely

25 rejected family life - "for at least a couple of years it was just stepping around each 
Self-starvation and the performance narrative

1 other, it wasn't like a family at all”. Holly went prolonged periods without speaking

2 to her parents and even withdrew from family holidays. Amidst this period, Holly was

3 invited to a netball national trial at only 14 years of age. The trial event, whereby top

4 performers compete for a place on the national representative team, was a significant

5 achievement and was praised at school. The gravity of the event also ensured that, for

6 the first time, Holly's mother saw an element of parity between sporting and academic

7 achievements. The trial duly became an opportunity to uphold the performance

8 narrative in a sporting context and achieve narrative realignment:

I think for once she'd (mother) kind of got involved in sport as much as I was and she wanted me to do well as much as I wanted to do well. Leading up to it we were doing it together and planning it together. So I think for once I kind of felt she gets that I’ve done well...so I think that it was pretty important for me, I thought it was important to do well so that things could carry on like that but then obviously things didn’t work out...it was right in the middle of it (family conflict/depression) and having the trial kind of lifted me out of it for a while because it was something to focus on and my mum was getting involved and for it (mother's involvement) to be cut off was a hell of a knock back really...the fact that things were straight back to how they'd been before This is the crux of Holly's narrative plight. She wants her achievements, sporting or otherwise, to be acknowledged above a cursory "well done”. Through the trial, and her mother's unexpected support of it, Holly is "lifted" out of her depressive state and re-engages with her family again. Representing her country in netball would bring with it the more crucial rewards of a sense of meeting parental expectations, narrative realignment and a wholly more contented existence. When the trial ends and 
Self-starvation and the performance narrative

1 Holly is unsuccessful, family life instantaneously reverts back to how it was. Holly's provides an unequivocal description of her feelings at this time:

I'd been knocked back in academics but I'd never really failed at the sport and it was the first time I hadn't made it and then it just felt like across the board, I just failed across the board really... it was not easy at all, the thing I was good at I was no longer good at. I was just left with nothing really, that's how it felt

What was an opportunity to bring Holly closer to culturally defined notions of achievement actually moved her further away. The remnants of self-worth, salvaged through the positive role of sport, were now also gone. Effectively, Holly's athletic identity is dealt a significant blow. She is unable to conceive of herself as an athlete and this threatens her sense of self. Failing “across the board” equates to loss of identity and a loss of self-worth. Holly is "left with nothing”.

\section{Understanding Disordered Eating: “Achieving” self-starvation?}

Soon after her unsuccessful England trial Holly began to severely restrict her food intake, a practice that she has maintained for over 6 years. For Holly, the meaning of disordered eating is fluid, multiple, and at times contradictory. As is illustrated in the ensuing section, her narrative weaves a complex understanding of self-starvation that holds potential consequences for her experience.

In the first instance, Holly recalls "definitely cutting down” on what she ate a month prior to the trial in a bid to become fitter. Although Holly states that her eating behaviours at this time were not "anything drastic" she would sometimes skip meals believing it would help her "perform better”. Engaging in disordered eating in the presence of sporting pressures to perform is consistent with the narrative governing the 'disordered eating in athletes’ literature (see Dosil, 2008). The aftermath of the trial however, saw Holly gradually withdraw from both netball and basketball. Holly's 
Self-starvation and the performance narrative

eating behaviours worsened rather than improved with the removal of sporting pressures, requiring her to construct a new narrative understanding: it just kind of became less about trying to be better and fitter and just into a rhythm I got into. Kind of punishing myself maybe a little bit. I just felt really bad about myself so...it's hard to explain. It was like a punishment I think and I'd feel guilty if I ate. Hearing all the comments about how bad I was and how much of a failure I was, I kind of believed it and just punished myself really Holly identifies her understanding of self-starvation as evolving from an issue of improving in sport to one of self-punishment. Other scholars have noted the link between eating disorders and a desire to self-punish (see Favazza, 2011). Given this new meaning, Holly develops her narrative account by interpreting her inability to fulfil the performance narrative as something to be punished via self-starvation. The expectations associated with telling a performance narrative have previously been linked to extreme dieting in competitive runners (Busanich et al. 2012). Paradoxically, as well as a means of punishment for not fulfilling a performance narrative, Holly also understands self-starvation as a form of achievement - "it's like the silliest thing but it's an achievement so...if I'm down on myself that can sometimes feel good to do that". She expanded: the times when I don't eat there is always, it sounds really bad, but there's always a part of you that feels good about being able not to do that...like if I can go a day or whatever, that's really sad but that's like an achievement...

The notion of self-starvation as a form of achievement is well-established in the literature (e.g. Granek, 2007; Ma, 2007). Arguing from a narrative perspective, we suggest that having exhausted culturally conventional narrations of achievement to no avail, Holly is forced to construct an 
Self-starvation and the performance narrative

1 alternative means for achievement in the form of not eating. Self-starvation is such a personal, non-normative conception of achievement that others are unable to rebuke it. Other than the substantial detriments to health, perceiving

4 severe food restriction as a source of achievement is also problematic because

5 it co-exists with an alternative and contradictory perspective: There's part of me that knows I should be, you know, eating normal, I should be having three meals a day and just managing that. So if I don't there’s a part of me which is just “why can’t I just do that like everyone else can do that?” but then the other part of me doesn't want to give in to doing that and feels better if I can manage not having three meals a day AP: How are you managing that difficult balancing act? ...it's not going so well at the minute. It's just outweighed at the minute by the part of me that wants to just get through the day without having to eat. It's just the stronger part at the minute.

Holly is unable to form a coherent meaning to her disordered eating experiences due to her commitment to two incompatible narratives. On the one hand, she considers regularly abstaining from eating as an accomplishment that increases her self-worth; on the other hand it constitutes an inability to conform to social norms thereby decreasing self-worth. Starvation is narrated as both an achievement and a failure. This mirrors Shohet's (2007) findings that women struggling to recover from an eating disorder narrate the experience as both good and bad. Echoing Shohet's study further, Holly’s narrative ambiguity breeds an inconsistent commitment to recovery: I’m not really making progress with it. I'm just kind of...just kind of...I'm not even dealing with it I'm just kind of going along day to day with it rather than 
Self-starvation and the performance narrative trying to you know move on from it and I don't think that something I can do on my own but where to go from here I just don’t know...

\section{Concluding Thoughts}

In this study we describe a performance narrative as a broad, cultural narrative that spans both academic and sporting auspices. Our narrative analysis suggests that this pervasive story can shape the self-starvation experiences of a young athlete. Holly initially understood her self-starving as a means to achieve in sport, but later interpreted it as a means to achieve in itself (see Ma, 2007). When the demands of a performance narrative render achievement opportunities scarce, self-starvation may be construed as the only means of achievement possible. How such disordered eating practices come to be understood as an achievement akin to scholarly or sporting pursuits is an important area for future research. Specifically, by what processes does a young female athlete understands dietary restriction as an accomplishment? In terms of the academic performance narrative, Holly's experiences echo the work of Evans, Rich, and Holroyd (2004) on performance codes and girls with eating disorders within the British schooling system. For them, the process is as such: performance codes, reflected in the intensification of school work, the increasing pressures wrought by examinations, assessment, expectations for achieving high grades at 'learning' and achievement in sport, have long been more than a passing concern for the young women in our study...It is hardly surprising that in such conditions some of these young women classified themselves and were classified by their psychologists as 'perfectionists'. In effect, the expedient, socially constructed conditions of intensified schooling produced by educational policy and practice had been interpolated as a 
Self-starvation and the performance narrative

psychological trait and their damaging consequences exacerbated as they intersected with other aspects of their lives. (Evans et al. p.131)

Evans and colleagues assert that the eating disorder behaviours of many young girls are not the result of individual flaws such as perfectionism but rather are born out of the cultural milieu of performance focused schooling. An environment of monitoring and control encourages individuals to monitor and control. Drawing from these insights, Holly’s incessant pursuit of achievement, as well as the distress and selfstarvation experienced at not achieving, can be viewed as partly a product of her school environment rather than her own personal weakness. To paraphrase Somers (1994), the public narrative determines the ontological narrative.

From the perspective of competitive sport, many of the features of an academic performance narrative also characterise what Douglas and Carless (2009) conceive as the performance narrative of elite sport. There is a joint narrative force then, acting on athlete-scholars such as Holly and further intensifying the pressure to achieve. For Holly, the cultural domains of sport and academia are certainly interrelated and it may be useful for health professionals, coaches and sport psychologists to be mindful of what is most likely a symbiotic relationship. Treating and supporting athletes with eating disorders must be a holistic endeavour that is sensitive to the different worlds an athlete inhabits at different times.

Holly described in detail the devastating consequences of living a life misaligned with a performance narrative. Her story demonstrates the power of cultural narratives to shape personal experiences. Holly experienced anger, resentment and depression. She withdrew from her school work and from the sporting activities she loved. She also told of a fractured family life and an isolated existence at home. The troubled relationship with a school teacher was also pivotal to Holly's personal story. 
Self-starvation and the performance narrative

1 These experiences marry well with the key themes identified by O’Shaughnessy et al.

2 (2013) in their study of the narratives of women with anorexia. Holly certainly told a

3 story of "loneliness" and "relationship troubles". The pressures of a performance

4 narrative contributed to what was a "threatening environment" for Holly. These novel

5 narrative insights contribute to a non-medicalized understanding of athlete eating

6 disorders. This study offers what too few in sport psychology have sought to offer; an

7 account of how an athlete lives through disordered eating on an emotional level (see

8 also Busanich et al., 2012; Papathomas \& Lavallee, 2006, 2010).

Practically, Lock, Epston, and Maisel (2004) suggest that narrative therapy can arm individuals with stories that counter destructive master narratives. This might involve a therapist collaborating with Holly to construct a counter-narrative that eschews the dominant achievement narrative or alternatively reconstructs her experiences as compatible with it. The first approach could involve storying factors other than normative achievement as important to self-worth - for example selfimprovement. The latter approach might involve forming a narrative that reframes Holly's sporting and academic successes as sufficiently worthy of the achievement narrative - tempering unrealistic demands. The crucial aspect of both approaches is to reconceptualise achievement. A study by Carless and Douglass (2012) provides a useful framework for countering the performance narrative and redefining achievement. For them, achievement can be conceived as 1.) effort and application 2.) embodied experience and discovery and/or (3) relationships and connections. Carless and Douglass emphasise that these more complex understandings of success are crucial to psychological health. Future research should explore how sport psychologists can facilitate athletes to adopt these healthier performance narratives 
Self-starvation and the performance narrative

Narrative therapy might also help alleviate the guilt and self-blame Holly experienced when she self-starved. The guilt can be seen as buying into a medical narrative that views disordered eating as very much an individual pathology. An appropriate counter-narrative in this instance might be to help Holly view the sheer force of the social influences, like school, sport and the family, which have shrouded her life experience, guided her actions and impacted on her identity. The goal is that she will no longer overplay her own role in her personal difficulties above a variety of other contributing social factors. Indeed, Holly's story itself may provide a counter to the medical-narrative for others to draw from. With research into narrative therapy as a treatment for eating disorders rare, sport psychologists must accumulate an evidence base if it is to become a recognised option for managing eating disorders in sport. To conclude, sporting practitioners must be aware of the broader cultural influences acting on athletes and the power they possess. Broader influences can often be as integral as the immediate sporting environment. The culture of competitive sport does not exist in a vacuum separate from the worlds of academia and the family. Each of these vast domains impacts on the other and as such, if eating disorders are to be addressed appropriately, practitioners should be open to all of the issues that an athlete might be faced with. Talk therapies such as counselling and narrative therapy can afford time for these wider issues to surface. Practitioners cannot afford to be blinkered by preconceived ideas as to why an athlete might be suffering with eating. Disordered eating is never straight forward, it is never a simple case of cause and effect and it is never easily treated. The best practice should, at least in the first instance, involve practitioners keeping an open mind as to the many factors that may be at play and, in narrative terms, attempting to tease out the "whole story". 
Self-starvation and the performance narrative

1

\section{References}

Andrews, M. (2002). Introduction: counter-narratives and the power to oppose. Narrative Inquiry, 12, 1-6.

Botha, D. (2009). Psychotherapeutic treatment for anorexia nervosa: Modernist, structural treatment approaches, and a post-structuralist perspective. Counselling, Psychotherapy, and Health, 5, 1-46. Retrieved from http://www.cphjournal.com/archive_journals/v5_1_Botha.pdf

Brewer, B.W., Van Raalte, J.L. and Linder, D.E., 1993. Athletic identity: Hercules’ muscle or Achilles' heel? International Journal of Sport Psychology, 24, 237254.

Busanich, R., McGannon, K. R., \& Schinke, R. J. (2012). Expanding understandings of the body, food \& exercise relationship in distance runners: A narrative approach. Psychology of Sport and Exercise, 13, 582-590. doi:10.1016/j.psychsport.2012.03.005

Carless, D. (2008). Narrative, identity, and recovery from serious mental illness: A life history of a runner. Qualitative Research in Psychology, 5, 233-248. doi:10.1080/14780880701826101

Carless, D., \& Douglass, K. (2012). Stories of success: cultural narratives and personal stories of elite and professional athletes. Reflective Practice: International and Multidisciplinary Perspectives, 13, 387-398. doi:10.1080/14623943.2012.657793

Charon, R. (2006). Narrative medicine: Honoring the stories of illness. New York: Oxford University Press. 
Self-starvation and the performance narrative

1 Cole, A.L., \& Knowles, J.G. (2001). Principles guiding life history researching. In A.L. Cole \& J. G. Knowles (Eds.), Lives in context: The art of life history research (pp. 25-44). New York: AltaMira Press.

Currie, A. (2007). A psychiatric perspective on athletes with eating disorders. Journal of Clinical Sport Psychology, 1, 329-339.

Dosil, J. (2008). Eating disorders in athletes. Chichester: Wiley.

Evans, J., Rich, E., \& Holroyd, R. (2004). Disordered eating and disordered schooling: what schools do to middle class girls. British Journal of Sociology of Education, 25, 123-142. doi:10.1080/0142569042000205154

Favazza, A. R. (2011). Bodies under siege: self-mutilation, nonsuicidal self-injury, and body modification in culture and psychiatry. Baltimore, MD: JHU Press.

Frank, A. W. (2007). Five dramas of illness. Perspectives in Biology and Medicine, 50, 379-394. doi:10.1353/pbm.2007.0027

Gergen, K.J, \& Gergen, M. (1988). Narrative and the self as relationship. In L. Berkowitz (Ed.), Advances in experimental social psychology (pp. 17-56). San Diego: Academic Press.

Granek, L. (2007). “You're a whole lot of person”-Understanding the journey through anorexia to recovery: A Qualitative Study. The Humanistic Psychologist, 35, 363-385. doi:10.1080/08873260701593367

Lock, A., Epston, D. Maisel, R. (2004). Countering that which is called anorexia. Narrative Inquiry, 14, 275-301.

Ma, J. L. (2007). Meanings of eating disorders discerned from family treatment and its implications for family education: the case of Shenzhen. Child \& Family Social Work, 12, 409-416. doi:10.1111/j.1365-2206.2007.00496.x 
Self-starvation and the performance narrative

1 McAdams, D. (1993). The stories we live by: Personal myths and the making of the self. New York: William Morrow.

McLeod, J. (1997). Narrative and psychotherapy. London: Sage.

4 McMahon, J., \& Dinan-Thompson, M. (2008). A malleable body - revelations from an Australian elite swimmer. Healthy Lifestyles Journal, 54, 1-6.

6 O'Shaughnessy, R., Dallos, R., \& Gough, A. (2013). A narrative study of the lives of women who experience anorexia nervosa. Qualitative Research in Psychology, 10, 42-62. doi:10.1080/14780887.2011.586100

Papathomas, A., \& Lavallee, D. (2006). A life history analysis of a male athlete with an eating disorder. Journal of Loss and Trauma, 11, 143-179. doi:10.1080/15325020500409192

Papathomas, A., \& Lavallee, D. (2010). Athlete experiences of disordered eating in sport. Qualitative Research in Sport and Exercise, 2, 354-370. doi:10.1080/19398441.2010.517042

Papathomas, A., \& Lavallee, D. (2012). Eating disorders in sport: A call for methodological diversity. Revista de Psicología del Deporte, 21(2), 387-392.

Petrie, T. A., \& Greenleaf, C. A. (2007). Eating disorders in sport: From theory to research to intervention. In G. Tenebaum \& R. C. Eklund (Eds.), Handbook of sport psychology (3rd ed., pp. 352-378). Hoboken, NJ: John Wiley \& Sons, Inc.

21 Phoenix, C., \& Smith, B. (2011). Telling a (good?) counterstory of aging: Natural bodybuilding meets the narrative of decline. The Journals of Gerontology Series B: Psychological Sciences and Social Sciences, 66, 628-639. doi:10.1093/geronb/gbr077 
Self-starvation and the performance narrative

1 Plummer, K. (2001). Documents of life 2: An invitation to a critical humanism. London: Sage.

3 Polkinghorne, D.E. (1988). Narrative knowing and the human sciences. Albany, NY: SUNY Press.

Rich, E. (2006). Anorexic dis(connection): Managing anorexia as an illness and an identity. Sociology of Health \& Illness, 28, 284-305. doi:10.1111/j.14679566.2006.00493.x

Riessman, C.K. (2008). Narrative methods for the human sciences. Thousand Oaks: Sage.

Shohet, M. (2007). Narrating anorexia: “Full” and "struggling” genres of recovery. Ethos, 35, 344-382. doi:10.1525/eth.2007.35.3.344

Smith, B., \& Sparkes, A. (2009) Narrative inquiry in sport and exercise psychology: What can it mean, and why might we do it? Psychology of Sport and Exercise, 10, 1-11. doi:10.1016/j.psychsport.2008.01.004

Smolak, L., Murnen, S., \& Ruble, A. E. (2000). Female athletes and eating problems: A meta-analysis. International Journal of Eating Disorders, 27, 371-380.

Somers, M.R. (1994). The narrative constitution of identity: A relational and network approach. Theory and Society, 23, 605-649.

Sparkes, A., \& Smith, B. (2013). Qualitative research methods in sport, exercise and health: From process to product. London: Routledge.

Torstveit, M. K., Rosenvinge, J. H., \& Sundgot-Borgen, J. (2008). Prevalence of eating disorders and the predictive power of risk models in female elite athletes: A controlled study. Scandinavian Journal of Medicine \& Science in Sports, 18, 108-118. doi:10.1111/j.1600-0838.2007.00657.x 